\title{
Oral health-related quality of life and the IOTN index as predictors of children's perceived needs and acceptance for orthodontic treatment
}

- There were inconsistencies in estimates of perceived orthodontic treatment need when using the IOTN and oral healthrelated quality of life $(\mathrm{OHRO} \mathrm{oL})$ measures.

- The IOTN index in combination with an OHROOL measure explained significantly more of children's perceived needs than the IOTN on its own.

- Additional subjective information using an OHRQoL measure would enhance orthodontic treatment need assessments.

\author{
C. M. de Oliveira, ${ }^{1}$ A. Sheiham, ${ }^{2}$ G. Tsakos ${ }^{3}$ and K. D. O'Brien ${ }^{4}$
}

VERIFIABLE CPD PAPER

\begin{abstract}
Objective To evaluate whether the index of orthodontic treatment need (IOTN) could be improved by adding an oral health-related quality of life measure to predict both the outcome of orthodontic consultation and the child's perceived need for orthodontic treatment. Methods The sample consisted of 187 children aged 11-16 years referred to orthodontic clinics in the Bedfordshire Personal Dental Service (PDS) in the United Kingdom. The children completed a questionnaire containing the Child Perception Questionnaire $\left(\mathrm{CPO}_{11-14}\right)$, were clinically examined and completed the Child-OIDP index in face-to-face interviews. Demographic information and perceived need for orthodontic treatment were also collected. Clinical data on orthodontic treatment need was collected using the IOTN. Results $49.3 \%$ of children reported one or more oral impacts. Combining the IOTN index with either of the two oral health-related quality of life measures used in this study did not predict outcome of consultation, however it explained children's perceived need for braces. There were some discrepancies between need according to the orthodontist and children's perceptions. Conclusions Adding an oral health-related quality of life measure to IOTN did not influence prediction of outcome of consultation but it explained the prediction of perceived need for braces. Importantly, children with an impact were denied orthodontic treatment.
\end{abstract}

\section{INTRODUCTION}

\section{Quality of life in dental research}

While quality of life has become a relatively common outcome measure in medical research, similar research in dentistry has begun to develop only recently. ${ }^{1}$ Traditionally, dental researchers have focused on clinician-driven

\footnotetext{
"Post-Doctoral Research Fellow in Orthodontics, School of Dentistry, University of Manchester, Higher Cambridge Street, Manchester, M15 6FH; ${ }^{2}$ Professor of Dental Public Health, ${ }^{3}$ Senior Lecturer in Dental Public Health, Department of Epidemiology and Public Health, University College London, Gower Street Campus, 1-19 Torrington Place, London, WC1E 6BT; ${ }^{4}$ Professor of Orthodontics, School of Dentistry, University of Manchester, Higher Cambridge Street, Manchester, M15 6FH

${ }^{*}$ Correspondence to: Dr Cesar de Oliveira

Email: cmdeoliveira@ hotmail.com
}

\section{Online article number E12}

Refereed Paper - accepted 7 September 2007

DOI: 10.1038/bdj.2008.239

${ }^{\circledR}$ British Dental Journal 2008; 204: E12 outcome measures at the expense of more subjective patient-driven measures, such as perceived functional status and psychological wellbeing. Furthermore, it is increasingly accepted that the measurement of oral health-related quality of life is an essential component of oral health surveys, clinical trials and other studies that evaluate the outcomes of preventive and therapeutic programs intended to improve oral health. This assessment has also an important role to play in clinical practice. ${ }^{2}$

of all the dental treatments that require the use of oral health-related quality of life measures, the treatment of malocclusion, which has such a large psychosocial component, calls out for the use of oral health-related quality of life measures. Paradoxically, despite the fact that demand for treatment is mostly related to personal concern about appearance and other psychological factors, morphologic change, measured by occlusal indices or cephalometric measures, has been the main criterion to assess both acceptance and effectiveness of orthodontic treatment. Unfortunately, this system reflects only the professional viewpoint and it is not always relevant to patients' functional or social requirements. Furthermore, it places relatively little emphasis on patients' perceptions of the need and the difference that orthodontic care may make to their daily lives. ${ }^{3}$

\section{Measures of oral health-related quality of life (OHROoL)}

The OHRQoL measures currently available for children are the Child Oral Health Quality of Life (COHQoL) questionnaire and the Child-Oral Impacts on Daily Performances (Child-OIDP)., 4,5-69 The Child Perception Questionnaire $\left(\mathrm{CPQ}_{11-14}\right)$ is a component of the COHQoL and was developed as an indicator with 
evaluative properties. The $\mathrm{CPQ}_{11-14}$ is aimed at evaluating symptoms, functional limitations, and emotional and social wellbeing in 11-14-year-old children. The $\mathrm{CPQ}_{11-14}$ has been tested on paediatric dentistry patients, orthodontic patients and patients with oro-facial conditions. The preliminary results indicate that it is valid and reliable.,

The Child-OIDP has been validated recently among children in Thailand, France and in the UK. ${ }^{5,10,11}$ It is derived from the OIDP ${ }^{12}$ and is based on an explicit conceptual framework, the World Health Organization (WHO) international classification of impairments, disabilities and handicaps (ICIDH), which has been amended for dentistry by Locker. ${ }^{13}$ It assesses the ability to perform daily activities, thus reflecting the ultimate outcomes of the WHO model. The OIDP is a short and easy-to-use instrument, which can be used for assessing oral health needs in population surveys, thus being potentially useful for planning services. It has also been used in cross-sectional surveys with the aim to discriminate between groups. It has acceptable psychometric properties and has been widely used among adolescents in different countries. ${ }^{14-17}$ The Child$\mathrm{OIDP}^{4}$ is based on the same conceptual framework and content, with modifications to suit children's capability in relation to their intellectual, cognitive and language development, as well as their memory ability. The Child-OIDP has a sound theoretical framework and has been shown to be a valid, reliable, and practical measure for Thai, French and British children. ${ }^{5,10,11}$

\section{Assessment of need for orthodontic treatment}

In the United Kingdom, the National Health Service (NHS) regulations state that NHS orthodontic treatment should be limited to patients with an Index of Orthodontic Treatment Need (IOTN) dental health component (DHC) of 4 or 5 and to patients with a DHC of 3 with an aesthetic component (AC) of 6 or more. ${ }^{18}$ While this system may limit the amount of orthodontic treatment provided, this measure only evaluates some aspects of entry into orthodontic treatment. Importantly, it does not evaluate the child's perception of need. This, arguably, may lead to denial of treatment to children with a genuine socio-dental need. As a result, a method of incorporating children' values into an evaluation of treatment need is required. This concept formed the focus for this study.

\section{MATERIALS AND METHODS}

We carried out a cross-sectional study of 187 children aged 11-16 years who were referred to orthodontic clinics in the Bedfordshire Personal Dental Service (PDS), United Kingdom, for provision of orthodontic diagnosis and treatment. The Orthodontic Personal Dental Services (PDS) Pilot Scheme in Bedfordshire Heartlands Primary Care Trust (PCT) is a pilot scheme that involves independent orthodontists, who have a contract to provide orthodontic treatment with the NHS, and aims to prioritise and provide orthodontic services to children with the greatest oral health need. ${ }^{19}$ In the UK orthodontic care is provided within the state funded NHS at no direct cost to the patients or parents. For a study testing a potential new measure of health, a sample size of 50 to 200 children has been recommended. ${ }^{20}$

\section{Ethical approval}

Ethical approval was obtained from the Brent Ethics Committee. The informative leaflets (parent and child) and the consent forms were sent to the prospective participant and his/her parents/guardians prior to their appointment. The relevant consent forms were signed by the participant and his/her parents. Only positive consent was accepted.

\section{Data collection}

The children and their parents/guardians were approached by the principal investigator (CO) and consent was obtained. The data collection procedure had two main stages. Initially, the children completed a questionnaire containing the Child Perception Questionnaire $\left(\mathrm{CPQ}_{11-14}\right)$ and also questions about children's perceived orthodontic treatment need and socio-demographic information. They were then interviewed for the Child-OIDP by the principal investigator (CO). The children were then seen by the orthodontist and the consultation
Table 1 Prevalence of oral impacts in each performance of the Child OIDP index $(n=187)$

\begin{tabular}{|l|l|}
\hline Performances & Prevalence (\%) \\
\hline Eating & 25.0 \\
\hline Speaking & 15.0 \\
\hline Cleaning teeth & 18.0 \\
\hline Relaxing & 7.0 \\
\hline Emotion & 9.0 \\
\hline Smiling & 24.0 \\
\hline School work & 3.0 \\
\hline Social contact & 15.0 \\
\hline At least one of the above & 49.3 \\
\hline
\end{tabular}

interview was tape recorded. This data was used to identify the outcome of the consultation. A child was identified as being accepted for treatment if they were offered treatment or placed on review for dental development or for a re-assessment of their oral hygiene. Finally, data on orthodontic treatment need according to IOTN was recorded by the orthodontists (CK, HT, SH, DC, MW, RD, JE).

\section{Statistical analysis}

The study had two main dependent variables. These were:

1. The outcome of the consultation - whether the child was accepted or not accepted for treatment (as defined above)

2. The child's perceived need for orthodontic treatment as expressed as their perception of the need, or not, for braces.

The predictive value of the baseline variables on outcome of consultation and child's perceived need for orthodontic treatment was evaluated with multiple logistic regression analysis. The following variables were entered into the model: (1) age, sex; (2) clinician-measured IOTN DHC; (3) Child-OIDP score or $\mathrm{CPQ}_{11-14}$ score. The relative merit of adding additional information to IOTN to predict both the outcome of consultation and the child's perceived need for orthodontic treatment was evaluated using the likelihood-ratio test. Thus, the relative merit of adding additional 
Table 2 Distribution of children according to their outcome of consultation, treatment need and oral health impact $(n=187)$

\begin{tabular}{l|l|l|l|}
\hline $\begin{array}{l}\text { Outcome of } \\
\text { consultation }\end{array}$ & Orthodontist IOTN DHC* & $\begin{array}{l}\text { Child-OIDP } \\
\text { no impact }\end{array}$ & $\begin{array}{l}\text { Child-OIDP } \\
\text { impact }\end{array}$ \\
\hline \multirow{2}{*}{$\begin{array}{l}\text { No treatment } \\
\text { recommended }\end{array}$} & Little need & $8(47.1 \%)$ & $9(52.9 \%)$ \\
\cline { 2 - 4 } & Borderline need & $8(61.5 \%)$ & $5(38.5 \%)$ \\
\cline { 2 - 4 } & Need & $6(75.0 \%)$ & $2(25.0 \%)$ \\
\hline \multirow{2}{*}{$\begin{array}{l}\text { Treatment } \\
\text { recommended }\end{array}$} & Little need & $5(50.0 \%)$ & $5(50.0 \%)$ \\
\cline { 2 - 4 } & Borderline need & $11(40.7 \%)$ & $16(59.3 \%)$ \\
\cline { 2 - 4 } & Need & $63(56.3 \%)$ & $49(43.8 \%)$ \\
\hline \multirow{2}{*}{ *Little need $=10 T N$ grades 1 and 2, borderline need $=10$ TON grade 3, need $=$ 10TN grades 4 and 5. } &
\end{tabular}

Table 3 Multiple logistic regression analysis to assess influence of IOTN and both oral health related quality of life measures variables (Child OIDP and $\mathrm{CPO}_{11}{ }_{14}$ ) on the outcome of the orthodontic consultation

\begin{tabular}{|c|c|c|c|c|}
\hline Dependent variable & Independent variables & $P$ value & $95 \% \mathrm{Cl}$ & OR \\
\hline \multirow{2}{*}{$\begin{array}{l}\text { Outcome of } \\
\text { consultation* }\end{array}$} & $\begin{array}{l}\text { Age } \\
\text { Sex** } \\
\text { Orthodontist IOTN DHC } \\
\text { Child-OIDP }\end{array}$ & $\begin{array}{l}0.158 \\
0.399 \\
<0.001 \\
0.133\end{array}$ & $\begin{array}{l}0.23-1.26 \\
0.61-3.35 \\
4.98-30.3 \\
0.97-1.24\end{array}$ & $\begin{array}{l}0.55 \\
1.44 \\
12.30 \\
1.10\end{array}$ \\
\hline & $\begin{array}{l}\text { Age } \\
\text { Sex** } \\
\text { Orthodontist IOTN DHC } \\
\mathrm{CPO}_{11-14} \text { score }^{\S}\end{array}$ & $\begin{array}{l}0.111 \\
0.380 \\
<0.001 \\
0.721\end{array}$ & $\begin{array}{l}0.22-1.16 \\
0.62-3.38 \\
4.99-29.6 \\
0.97-1.03\end{array}$ & $\begin{array}{l}0.51 \\
1.46 \\
12.16 \\
1.00\end{array}$ \\
\hline $\begin{array}{l}{ }^{*} 0=\text { no treatment, } 1=\text { treatr } \\
{ }^{* *} \text { Sex: } 1=\text { boy, } 2=\text { girl } \\
+ \text { As IOTN score increases, ne } \\
{ }^{*} \text { As Child OIDP score increas } \\
\text { \$As CPQ } 111 \text { score increases, }\end{array}$ & $\begin{array}{l}\text { tment increases } \\
\text { alth impact increases } \\
\text { impact increases }\end{array}$ & & & \\
\hline
\end{tabular}

information to IOTN to predict use of orthodontic services was evaluated. The Statistical Package for Social Sciences program (SPSS Inc., 444 Michigan Avenue, Chicago, USA) version 13 and the Stata 7.0 program (Stata, College Station, Tex) were used for data analysis. Statistical significance was set at the 5\% level.

\section{RESULTS}

One hundred and eighty-seven children were invited to participate in the study and none refused or were unable to complete the questionnaire due to literacy problems. The mean age of participants was 12.21 years $(\mathrm{SD}=1.8)$. There were 98 girls (52.4\%) and 89 boys (47.6\%). Most (156, or 83.4\% were white British (83.4\%), $21(11.2 \%)$ Asian and 10 children (5.4\%) were from other ethnic backgrounds. Sixty percent (112) of the children had higher deprivation scores compared to 40\% (75) with lower deprivation scores measured by the Index of Multiple Deprivation. Most (120, or 64.2\%) of children had a great orthodontic treatment need (grades 4 and 5) according to the dental health component of the IOTN index. Forty (21.4\%) children had borderline need (grade 3) and 27 (14.4\%) had little need (grades 1 and 2).

Overall, 49.3\% of children reported at least one oral impact affecting their daily performance in the past three months according to the Child-OIDP index. The most prevalent impact was difficulty in eating (25\% of children), followed by impacts on smiling (24\%), cleaning the teeth (18\%), social contact (15\%) and speaking (15\%). Doing schoolwork and relaxing were the least prevalent impacts, occurring in 3\% and $7 \%$ of children in the sample (Table 1 ). The mean $\mathrm{CPQ}_{11-14}$ overall score was 18.41 ( $S D=13.7)$. The mean score for the $\mathrm{CPQ}_{11-14}$ subscales were as follows: oral symptoms $4.96(\mathrm{SD}=2.92)$, functional limitations $5.21(\mathrm{SD}=4.00)$, emotional wellbeing $4.53(\mathrm{SD}=5.32)$ and social wellbeing 3.71 ( $\mathrm{SD}=4.92)$.

Table 2 includes data on the orthodontists' clinical assessment using IOTN and children's perceived need for treatment. This reveals that there were important discrepancies between the orthodontists and the child's perception of need. For example, 63 children selected for orthodontic treatment and with a higher clinical need (IOTN grades 4 and 5) did not report any oral health impact. On the other hand, eight children were discharged despite having a higher clinical need (IOTN grades 4 and 5) and two $(25 \%)$ of them had an oral health impact. Additionally, five children discharged and with a borderline clinical need (IOTN grade 3) had an oral health impact. On the other hand, 11 children with a borderline clinical need and who were selected for treatment did not report any oral health impact. Five (50\%) children with a very low clinical need (IOTN grades 1 and 2) and who were selected for treatment had an oral health impact. Conversely, nine children discharged and with low clinical need reported at least one oral health impact. Moreover, 16 out of 79 children accepted for treatment had little/borderline need and did not report any oral health impact.

Table 3 includes the results of the multiple logistic regression analysis of the relationship between overall oral health impact (Child-OIDP and $\mathrm{CPQ}_{11-14}$ ) and outcome of orthodontic consultation. A child with higher normative clinical treatment need was 12 times more likely to receive orthodontic treatment than a child with low clinical need ( $p<0.001)$. Both oral health-related quality of life measures tested in the present study did not predict the outcome of consultation. The likelihood-ratio test value demonstrated that adding either the childOIDP or the $\mathrm{CPQ}_{11-14}$ variable into the multiple regression analysis to predict the outcome of consultation was not statistically significant.

Table 4 includes the results of the multiple logistic regression analysis of the relationship between overall oral health impact (Child-OIDP and $\mathrm{CPQ}_{11-14}$ ) and children's perceived need for orthodontic treatment. Interestingly, IOTN scores 
Table 4 Multiple logistic regression analysis to show influence of IOTN and both oral health related quality of life measures variables (Child OIDP and $\mathrm{CPO}_{11}{ }_{14}$ ) on child's perceived need for a brace

\begin{tabular}{|c|c|c|c|c|}
\hline Dependent variable & Independent variables & $P$ value & $95 \% \mathrm{Cl}$ & OR \\
\hline \multirow{2}{*}{$\begin{array}{l}\text { Perceived need } \\
\text { for a brace* }\end{array}$} & $\begin{array}{l}\text { Age } \\
\text { Sex } \\
\text { Orthodontist IOTN DHC } \\
\text { Child-OIDP* }\end{array}$ & $\begin{array}{l}0.002 \\
0.669 \\
0.258 \\
0.050\end{array}$ & $\begin{array}{l}0.18-0.69 \\
0.47-1.62 \\
0.76-2.75 \\
1.00-1.13\end{array}$ & $\begin{array}{l}0.36 \\
0.87 \\
1.45 \\
1.06\end{array}$ \\
\hline & $\begin{array}{l}\text { Age } \\
\text { Sex }^{* *} \\
\text { Orthodontist IOTN DHC } \\
\mathrm{CPO}_{11-14} \text { score }^{\S}\end{array}$ & $\begin{array}{l}0.001 \\
0.566 \\
0.213 \\
0.029\end{array}$ & $\begin{array}{l}0.17-0.64 \\
0.44-1.55 \\
0.79-2.87 \\
1.00-1.05\end{array}$ & $\begin{array}{l}0.33 \\
0.83 \\
1.51 \\
1.03\end{array}$ \\
\hline \multicolumn{5}{|c|}{ 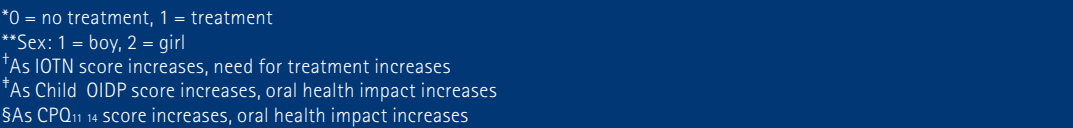 } \\
\hline
\end{tabular}

were not related to the child's perceived need for orthodontic treatment. Both oral health-related quality of life measures tested in the present study did predict the child's perceived need for orthodontic treatment. Additionally, the likelihood-ratio test value demonstrated that adding the Child-OIDP variable into the multiple regression analysis to predict a child's perceived need for orthodontic treatment was statistically significant ( $p$ $<0.04)$. Similarly, the likelihood-ratio test value for the $\mathrm{CPQ}_{11-14}$ variable was also statisticallysignificant ( $p<0.02)$.

\section{DISCUSSION}

Our main findings were that almost half of the children referred for an orthodontic assessment reported an oral health impact on their daily lives and this impact was related to the children's perceived need for orthodontic treatment. However, this did not influence whether they were offered orthodontic treatment as this was governed by IOTN scores. Furthermore, the study demonstrated that adding an oral health-related quality of life measure (Child-OIDP and $\left.\mathrm{CPQ}_{11-14}\right)$ to the IOTN index did not predict outcome of consultation. This finding is supported by Mandall et al. ${ }^{21}$ who reported that socio-dental indicators did not predict uptake of orthodontic services. The lack of influence of both oral health-related quality of life measures used in the present study on the outcome of consultation could be explained by the fact that within the NHS the IOTN index has an overruling influence on whether a child is accepted for orthodontic treatment.

However, this study provides some evidence that the IOTN index when used in combination with either of the two oral health-related quality of life measures, explained significantly more of children' perceived need for orthodontic treatment than the IOTN on its own. This illustrates the value of combining a normative with an oral health-related quality of life measure.

One of our most important findings was that there were inconsistencies in the present system of assessing the need for orthodontic treatment. The discrepancies highlighted in the present study between clinical need and child's perceived need are supported by the findings of de Oliveira and Sheiham, ${ }^{17}$ where relatively high percentages of children who were assessed to have orthodontic treatment need by the IOTN index did not have any oral health impact. Moreover, $12.6 \%$ of adolescents who had no or only a slight IOTN need for orthodontic treatment were still dissatisfied with the appearance of their teeth. Similarly, the 2003 UK National Child Dental Health Survey found that not all parents and children agreed with a professionally assessed need for treatment. For example, $58 \%$ of the parents of 12-yearold children with a clinical need (and not already under treatment) felt that their children did not need orthodontic treatment. ${ }^{22}$ It is not difficult to put forward good reasons for these discrepancies. For example, an unerupted tooth scores highly in IOTN (DHC = 5i). However, if this is not visible to the child it is unlikely to have a socio-dental impact.

This study was carried out in a sample of children referred for orthodontic assessment, so presumably there was some perception of orthodontic need amongst them. This factor may have influenced the results since some of the children may have been aware of the topics explored by this research. On the other hand, a survey of nonreferred children is likely to show even higher discrepancies.

Clearly, from the NHS commissioning perspective there are important resource issues when considering the feasibility of incorporating a socio-dental measure into the evaluation of orthodontic need. However, the benefits of incorporating a socio-dental measure are likely to result in a lower demand for orthodontic treatment, as only a proportion of those assessed on the IOTN index would have a socio-dental impact. In addition, the proposed approach is likely to result in an improved treatment priority setting, since treatment would first be provided to those who would benefit the most. Consequently, a more efficient use of resources would be achieved.

Under the current system of orthodontic provision, children with a socio-dental impact are being denied treatment or, paradoxically, those with no impact are being treated. We must conclude that a system that is based on IOTN alone leads to wasted resource or denial of orthodontic care.

\section{CONCLUSIONS}

1. The outcome of consultation was heavily influenced by the IOTN index and adding an oral healthrelated quality of life measure to IOTN index did not significantly influence treatment prediction

2. The perceived need for treatment was supported by the oral healthrelated quality of life measures used but not by the IOTN. The IOTN index was not valid as it did not reflect children' values, nor was it 
influenced by children's perceptions (eg impacts)

3. The study highlighted some discrepancies between the decision to provide orthodontic treatment based on the IOTN index and children's perceptions, and suggests that it is essential to incorporate a sociodental measure into the evaluation of need and outcome of orthodontic treatment.

The authors would like to thank the Bedfordshire Orthodontic Personal Dental Service (PDS) team for their participation in this project. PDS list of orthodontists: Mr Chris Kettler, Mrs Helen Turner, Miss Samantha Hindle, Mr John S. K. Evans, Mr Duncan Chappell, Mr Mark Wolkenstein, Mrs Rita Darbar and Mr Yunnus Mohamed. We are also grateful to Ms Sue Gregory, the Consultant in Dental Public Health, for her considerable support.

1. Hatch J P, Rugh J D, Clark G M, Keeling S D, Tiner B $D$, Bays $R$ A. Health related quality of life following orthognatic surgery. Int J Adult Orthod Orthognath Surg 1998; 13: 67-77.

2. Locker D, Matear D, Stephens M, Lawrence $H_{1}$ Payne B. Comparison of the GOHAI and OHIP-14 as measures of the oral health-related quality of life of the elderly. Community Dent Oral Epidemiol 2001: 29: 373-381.

3. O'Brien K D, Wright J L, Conboy F, Macfarlane T, Mandall N. The child perception questionnaire is valid for malocclusions in the United Kingdom. Am
J Orthod Dentofacial Orthop 2006; 129: 536-540.

4. Jokovic A, Locker D, Stephens M, Kenny D, Tompson B, Guyatt G. Validity and reliability of a questionnaire for measuring child oral-health-related quality of life. J Dent Res 2002; 81: 459-463.

5. Gherunpong S, Tsakos G, Sheiham A. Developing and evaluating an oral health-related quality of life index for children; the CHILD-OIDP. Community Dent Health 2004; 21: 161-169.

6. Jokovic A, Locker D, Stephens M, Guyatt G. Agreement between mothers and children aged 11-14 years in rating child oral health-related quality of life. Community Dent Oral Epidemiol 2003; 31: 335-343.

7. Jokovic A, Locker D, Stephens M, Kenny D, Tompson $B$, Guyatt $G$. Measuring parental perceptions of child oral health-related quality of life. J Public Health Dent 2003; 63: 67-72.

8. Locker D, Jokovic A, Stephens M, Kenny D, Tompson B, Guyatt G. Family impact of child oral and oro-facial conditions. Community Dent Oral Epidemiol 2002; 30: 438-448.

9. Jokovic A, Locker D, Tompson B, Guyatt G. Questionnaire for measuring oral health-related quality of life in eight to ten year-old children. Pediatr Dent 2004; 26: 512-518.

10. Tubert-Jeannin S, Pegon-Machat E, GremeauRichard C, Lecuyer M-M, Tsakos G. Validation of a French version of the Child-OIDP index. Eur J Oral Sci 2005; 113: 355-362.

11. Yusuf H, Gherunpong S, Sheiham A, Tsakos G. Validation of an English version of the Child-OIDP index, an oral health-related quality of life measure for children. Health Qual Life Outcomes 2006; 4: 38. doi: 10.1186/1477-7525-4-38

12. Adulyanon $S$, Sheiham A. Oral impacts on daily performances. In Slade G D (ed) Measuring oral health and quality of life. pp 151-160. Chapel Hill, NC, USA: Dental Ecology, University of North Carolina, 1997.
13. Locker D. Measuring oral health: a conceptual framework. Community Dent Health 1988; 5: 3-18.

14. Masalu J R, Astrom A N. Applicability of an abbreviated version of the oral impacts on daily performances (OIDP) scale for use among Tanzanian students. Community Dent Oral Epidemiol 2003; 31: 7-14.

15. Astrom A N, Okullo I. Validity and reliability of the oral impacts on daily performance (OIDP) frequency scale: a crosssectional study of adolescents in Uganda. BMC Oral Health 2003; 3: 5.

16. Cortes M I, Marcenes W, Sheiham A. Impact of traumatic injuries to the permanent teeth on the oral health-related quality of life in 12-14-year-old children. Community Dent Oral Epidemiol 2002; 30: 193-198.

17. de Oliveira C M, Sheiham A. The relationship between normative orthodontic treatment need and oral health-related quality of life. Community Dent Oral Epidemiol 2003; 31: 426-436.

18. Strategic commissioning of primary care orthodontic services. London: Department of Health 2006, gateway reference no. 7105 .

19. Kettler C J. The bedfordshire PDS orthodontic pilot. BrJ Orthod 1999; 26: 342-345.

20. Stewart A L, Hays R D, Ware J E Jr. Methods of constructing health measures. In Stewart A L, Ware J E Jr (eds) Measuring functioning and well-being. The medical outcomes study approach. pp 67-85. Durham and London: Duke University Press, 1992.

21. Mandall N A, Wright J L, Conboy F, Kay E, Harvey L, O'Brien K D. Index of orthodontic treatment need as a predictor of orthodontic treatment uptake. Am J Orthod Dentofacial Orthop 2005; 128: 703-707.

22. Chestnutt I, Pendry L, Harker R. The orthodontic condition of children in the UK 2003. In Children's dental health in the UK 2003. London: Office of National Statistics, 2004 